\title{
EMPLOYEE PARTICIPATION IN MANAGEMENT, BARGAINING POWER AND WAGES
}

\author{
Jan SVEJNAR* \\ Cornell University, Ithaca, NY 14853, USA
}

Received August 1980, final version received August 1981

\begin{abstract}
The paper analyzes the impact of employee participation in management on bargaining power and wages. It presents an empirical model which allows for variable bargaining powers of the parties who jointly control the firm and it tests this model with postwar West German data. The results suggest that 'parity codetermination' has had a positive effect on earnings in iron and steel but not in coal mining. Moreover, it appears that the positive effect in iron and steel could be due to increased profitability rather than an increase in the bargaining power of labor as defined in this study.
\end{abstract}

\section{Introduction}

Since the early 1970's there has been a definite trend in many Western European countries toward establishing some form of employee participation in management and this trend is likely to continue. The main stimulus for this on-going change has been the reversal of many trade unions on this issue. Until recently, most Western trade unions (except for the German and Austrian unions) were opposed to the idea of participation in management. Once they turned in favor of participation, however, they promoted it and usually succeeded in having a limited form of employee participation legally founded. ${ }^{1}$

* I would like to thank Orley Ashenfelter, Gerald Epstein, Edward Green, Arvind Panagariya, Louis Phlips, Albert Rees, Robert Solow and two anonymous referees for helpful comments on earlier drafts of this paper. This research was in part supported by a grant from the Council for European Studies and a grant to the Princeton University Economics Department from the Sloan Foundation.

${ }^{1}$ Since 1973 two worker representatives have been allowed to sit on each Board of Directors in Sweden, and a virtually identical arrangement has existed in Denmark since 1974. In Austria and Luxembourg worker representatives have occupied one-third of the seats on the Boards since 1974. Similarly, in Norway employees have had since 1973 the option of filling one-third of the Board seats with their representatives. In the Netherlands workers have an indirect voice in deciding the membership of the Supervisory Board. In Britain the situation is in a state of flux. The Labour Party pushes for participation and the Trade Unions Congress advocates the inclusion of union representatives on the Boards on a parity basis with the other members. Many trade unions affiliated with the T.U.C., however, still reject this form of participation. As recent debates over the Bullock report indicate, the outcome is not clear. Finally, proposals of the Commission of the European Economic Community $(1970,1975)$ for a statute for a European Company suggest that the German-type representation (discussed later) may in the future be adopted by the entire European Community. For a more detailed discussion of the underlying institutional factors and the extent of actual participation, see Schregle (1976) and Windmuller (1977).

0014-2921/82/0000-0000/\$02.75 (C) 1982 North-Holland 
In the debates that have accompanied the establishment of employee participation it has often been argued that participation will, among other things, increase labor's power relative to that of management and shareholders. The question then arises as to whether this might also lead to an increase in labor's income relative to that of the other two groups. Unfortunately, theoretical work on the economic impact of worker participation has ignored this issue, primarly because of the absence of a theoretical specification with a natural characterization of 'labor's power'. ${ }^{2}$ In addition, the existing empirical material on this subject is primarily institutional with only sketchy quantitative analysis. ${ }^{3}$

This paper presents an econometric framework for analyzing the effects of participation on labor's bargaining power and wages, and empirical evidence based on available data from the Federal Republic of Germany.

The German experience with employee participation is unique in that it is quite extensive and diverse, thus providing testable examples of at least two different participatory systems. One was created by the 1951 Codetermination Act which granted employees in the coal mining and the iron and steel industries fifty percent (parity) representation on the Boards of Directors ${ }^{4}$ of their enterprises. In addition, the Act created the position of a labor director on all Management Boards. The labor director, appointed by the Board of Directors, is responsible for the Management Board's labor policies. Because he cannot be appointed or dismissed without majority approval of the employee representatives to the Board of Directors, he tends to be a pro-labor force on the Management Board [see Vollmer (1976) and Fürstenberg $(1969,1977)]^{5}$

The second system was created by the 1952 Works Constitution Act which provided employees in all but the shipping and air-transport industries with thirty-three percent representation on the Boards of Directors. Thus while employees in iron-steel and coal mining obtained parity representation on the Boards of Directors and control over the labor post on the Management Boards, their counterparts in other industries were given only thirty-three percent of the seats on the Boards of Directors. This distinction is important for two reasons. First, in the German system employee representatives to the Boards of Directors take part in the Boards' deliberations and decision-making concerning collective bargaining agree-

\footnotetext{
${ }^{2}$ Steinherr's (1977) model could conceivably accommodate this aspect but Steinherr does not develop the model in this direction.

${ }^{3}$ Studies which attempted to analyze the relationship between participation and labor income are those of Blumenthal (1956, pp. 70-89) and Sturmthal (1964, pp. 76-79). They use only a loose quantitative approach, however, and provide no formal model for the analysis.

${ }^{4}$ Unlike the single-board Anglo-American system, the German system is based on two boards: the Board of Directors (Aufsichtsrat) and the Management Board (Vorstand).

${ }_{5}^{5}$ Recently, the 1976 Codetermination Act extended a modified version of the 1951 Act to all firms in the German economy with a workforce over 2,000 [see Vollmer (1976)].
} 
ments and industrial disputes. ${ }^{6}$ Secondly, the labor director has considerable discretion over the wage determination process at the firm level. While it is true that wage rates are usually set in an industry-wide agreement between the trade union and the employer association, the actual wage may considerably exceed the rates set in the master agreement at the industry level. ${ }^{7}$

It should also be noted that within the 1951 Codetermination Act an important distinction exists between the roles of the labor directors in the iron-steel and coal mining industries. While the labor directors of the iron and steel companies are appointed by their firms to the industry's employer association and some of them join the association's bargaining committees in the industry-wide wage negotiations, the labor directors from coal mining companies do not participate at all in the activities of their employer association. This in turn raises the question of whether the impact of the 1951 law on labor's bargaining power and wages is greater in iron-steel than in coal mining. The particular position of labor directors in the iron and steel industry may be an important factor affecting labor's power. The 1951 law in effect gives the (pro-labor) labor directors influence within the employer ranks over the industry-wide as well as firm-specific wage negotiations. This 'conflict of interest' is considered so serious by the German Federation of Employer Associations that it excludes the Iron and Steel Industry Employer Association from its membership. ${ }^{8}$

In general, if more extensive forms of employee participation generate greater real gains in labor's power relative to that of managers and shareholders, then one would expect greater income gains for labor the greater the extent of employee representation. The next section develops this idea more formally.

\section{The conceptual framework}

Analytically, the German codetermination system corresponds to a bilateral monopoly between labor and management where, for expositional simplicity, management is taken to represent the interests of shareholders as

\footnotetext{
${ }^{6}$ See Schregle (1976). Another form of employee participation which exists in all industries is the Works Councils. They have legally operated in German companies since 1946 and their role was clearly defined by the 1952 and 1972 Works Constitution Acts. While the effects of this form of participation strengthen the conclusions of the conceptual model, the quantitative effects are not explored in this study.

${ }^{7}$ A 1955 study carried out by the German Metalworkers' Union indicates that the average differential between the actual wage rates and the industry contract rates was 16.4 percent and that it was greatest (27.7 percent for males) in iron production. Recently Vollmer (1976) reported that plant agreements raise wage rates by as much as 40 percent over the industry-set agreements.

${ }^{8}$ I am grateful to John Windmuller for pointing out this important aspect of the 1951 law to
} 
well. ${ }^{9}$ In the bilateral monopoly framework conventional economic analysis fails to generate a definite outcome (settlement) between the two parties. However, under the assumption of Pareto efficiency, economic models can isolate the so called 'zone of possible settlements' or 'contract curve' within which the settlement between two rational partners should occur. ${ }^{10}$ Most institutional studies of industrial relations in turn attribute the determination of the actual settlement to the relative bargaining power of the two parties. ${ }^{11}$

In the present paper an estimating equation is formulated which combines - the notion of both a contract curve and a settlement which is determined by the relative bargaining power of labor and management. Begin by letting the firm's actual profit, calculated net of labor cost, be

$$
\tilde{\pi}=P Q-m M-r K-\pi,
$$

where $P=$ the product price, $Q=$ the volume of output, $m=$ the managerial salary, $M=$ the number of managers, $r=$ the market rate of return on capital, $K=$ the amount of capital used by the firm, and $\pi_{0}=$ other costs (e.g. fixed costs). The actual profit net of labor cost, $\tilde{\pi}$, represents the amount which the two parties jointly generate and distribute between labor income (cost), WL, and the firm's residual profit

$$
\hat{\pi}=P Q-W L-m M-r K-\pi_{0},
$$

where $W=$ the negotiated wage and $L=$ the number of workers employed by the firm. ${ }^{32}$

In bargaining for the highest possible wage, $W$, workers are assumed to take into account their best alternative (market) wage, $W^{a}$, which they could earn with certainty elsewhere. More realistically, this best alternative wage summarizes a distribution of alternative wages that workers face with various probabilities in alternative jobs. If rational workers are unwilling to settle (stay with the firm) at a wage which is lower than $W^{a}\left(W<W^{a}\right)$, then the subject of bargaining between the two parties is given by the 'net profit'

$$
\pi=\bar{\pi}-W^{\mathrm{a}} L=P Q-W^{\mathrm{a}} L-m M-r K-\pi_{0} .
$$

The net profit, $\pi$, represents the residual surplus generated by the firm after

\footnotetext{
9This simplification is quite reasonable given that, with the exception of the 'neutral' member, the non-employee representatives to the Board of Directors are shareholders. Moreover, the model also applies to situations where managers are totally independent of shareholders since all the subsequent analysis can be cast in terms of more than two parties. See Svejnat (1982b).

${ }^{10}$ The economic notions of the range and boundaries to the bargain were first extensively formulated as 'limits to coercion' by Commons (1934) and as 'range of indeterminateness' by Pigou (1938).

${ }^{11}$ See, for instance. Chamberlain and Kuhn (1951) and Kochan (1980).

${ }^{12}$ Strictly speaking, $W$ should be taken to represent the total compensation package per worker.
} 
all inputs have been paid their best alternative (market) prices. The division of $\pi$ between the two parties is presumably determined by their relative bargaining power. In order to make this concept operational, let us define a measure of labor's bargaining power as a share $\gamma(0 \leqq \gamma \leqq 1)$ of the net profit, $\pi$. It then follows from eqs. (1) and (3) that the negotiated wage (compensation package) equals

$$
W=W^{a}+\gamma(\pi / L) .
$$

If $\gamma=0$, workers have no bargaining power. They merely obtain the best alternative wage $\left(W=W^{a}\right)$ and the net profit, $\pi$, goes entirely to the management party. This situation corresponds to a perfectly competitive labor market. On the other hand, if $\gamma=1$ it follows that $W=W^{\mathrm{a}}+\pi / L=$ $\tilde{\pi} / L$. This scenario reflects a fully labor-managed firm where workers appropriate all the net profit. In this case managers and shareholders have no bargaining power, $1-\gamma=0$, and they merely receive the market prices $m$ and $r$ for supplying their respective services.

Eq. (4) lends itself to econometric estimation and the results based on (4) are reported in the next section. Before turning to the empirical results, however, it is useful to discuss briefly the relationship of the model in eq. (4) to some of the relevant game-theoretic literature and to examine the appropriateness of this model for analyzing outcomes in the West German system.

In the foregoing discussion, eq. (4) has been posited directly and justified in terms of its correspondence to the economic and the institutional industrial relations literature. However, under appropriate specifications, the same equation can be derived as a reduced form from the game-theoretic models of Nash (1950, 1952), Kalai (1977) and Svejnar (1982b). Eq. (4) is therefore an appealing characterization of bargaining outcomes not only because it is in harmony with the existing economic and industrial relations notions, but also because it can be derived from a set of presumably broadly acceptable axioms.

In applying the model of eq. (4) to the German codetermination system two points ought to be considered. First, since the model incorporates the economic principle of Pareto-efficiency, it is incompatible with income losses which are under the control of the two parties. The model would therefore not be easily applicable in countries such as the United States or Great Britain, where strikes and/or lockouts are relatively frequent. ${ }^{13}$ The German system of industrial relations, however, is known for its extreme paucity of strikes and lockouts. Moreover, the establishment of codetermination augmented considerably the information flow between labor and management.

\footnotetext{
${ }^{13}$ For examples of models which explicitly incorporate strikes, see for instance Ashenfelter and Johnson (1969) and Farber (1978).
} 
This makes much more realistic the assumption of perfect knowledge, which is often invoked as a justification for Pareto-efficient behavior.

Secondly, since the model treats the case of a bilateral monopoly, it is worth reiterating that the German system, with its high degree of unionization and industry-level bargaining between the employer association and a given trade union, fits this framework very well. The trade unions are organized along industry lines (one union per industry) and are tightly knit into a nation-wide confederation representing almost fifty percent of the labor force.

\section{The econometric model}

Eq. (4) provides an interesting theoretical restriction, namely that the coefficient on $W^{\text {a }}$ equals unity. For purposes of econometric estimations it is also important to realize that if participation raises labor's power from $\gamma$ to $\gamma^{*}$, then, for a time series covering the periods both before and after the advent of participation, eq. (4) becomes

$$
W_{t}=W_{t}^{a}+\gamma(\pi / L)_{t}+\Delta \gamma(\pi / L)_{t} D_{t}
$$

where $\Delta \gamma=\gamma^{*}-\gamma, D_{1}=1$ after the introduction of participation and $D_{t}=0$ before it. ${ }^{14}$

In principle, the coefficients $\gamma$ and $\Delta \gamma$ can be estimated directly from eq. (5). Unfortunately no data exist on net profit, $\pi_{t}$, for the periods before and immediately after the introduction of participation. As a result, using the available data, two different approaches are taken to approximate $\pi_{t}$.

In the first approach it is assumed that $\pi_{t}$ and ( $\left.W^{a} L\right)$, vary proportionately and hence $\left(\pi / W^{a} L\right)_{t}$ is a constant, say $k$. While the validity of this assumption (the constancy of labor's share in the net profit) cannot be ascertained, the approach enables us to answer the important question of whether or not the advent of participation has been accompanied by a change in relative wages. In particular upon substituting $\left(\pi / W^{a} L\right)_{t}=k$ into (5), the estimating equation becomes

$$
\left(W_{1}-W_{\mathfrak{\imath}}^{a}\right) / W_{1}^{a}=\gamma k+\Delta \gamma k D_{\imath},
$$

or

$$
W_{\mathrm{t}} / W_{\mathrm{t}}^{\mathrm{a}}=1+\gamma k+\Delta \gamma k D_{\mathrm{t}}
$$

\footnotetext{
14 There are two ways to model the maximizing behavior of the codetermined firm. In the first case the two parties maximize the joint profit and bargain over its division. In the second scenario joint maximizing behavior is not assumed and managers maximize only their residual profit, $\hat{\pi}$. Both approaches generate eqs. (4) and (5). However, for econometric purposes it must be noted that in the first case $L$ is exogenous, whereas in the second case it is endogenous. In view of the cooperative nature of codetermination, the first case is deemed more appropriate here. See also Svejnar (1982b).
} 
Eqs. (6) and (7) can be estimated directly and the increase in labor's bargaining power can be calculated from the ratio $\Delta \gamma k / \gamma k=\Delta \gamma / \gamma$. However, the specifications in (6) and (7) do not permit us to test the prediction found in eq. (4), namely that the coefficient on $W^{\mathrm{a}}$ is equal to unity. At the same time the test of this restriction is particularly useful since we are forced to approximate $\pi_{t}$. Fortunately, since $\left(W_{t}-W_{t}^{a}\right) / W_{t}^{a} \simeq \ln \left[1+\left(W_{t}-W_{t}^{a}\right) / W_{t}^{a}\right]=$ $\ln W_{1}-\ln W_{t}^{a}$, eq. (6) can be written as

$$
\ln W_{t}=\ln W_{t}^{a}+\gamma k+\Delta \gamma k D_{t}+e_{t},
$$

where the error term, $e_{t}$, is assumed to have zero mean and be homoscedastic and independent of the explanatory variables. In eq. (8) the theoretical restriction of a unitary coefficient on $\ln W_{t}^{\mathrm{a}}$ can be tested without imposing it on the data directly as in (6) and (7). Moreover, if the restriction is empirically supported, the estimate of $\Delta \gamma k$ in (8) should be virtually identical with that in (6) or (7).

The second approach is based on the plausible assumption that the net profit varies in proportion to the revenue, $P Q=\beta \pi$, with $\beta>1$. Since $\pi=P Q-T C$, where the total cost is defined as $T C=W^{a} L+m M+r K+\pi_{0}$, the assumption $P Q=\beta \pi$ implies that the total cost also varies in proportion to the net profit, $T C=(\beta-1) \pi$, where $\beta-1>0$. Factor costs usually vary directly with profit and therefore the bias created by the approximation $P Q=\beta \pi$ may not be serious. Since data could be obtained directly for $W^{a}$ and $L$, and in index form for $P$ and $Q$, the approximation used in this second approach is given by

$$
\left(\pi / W^{\mathrm{a}} L\right)_{t} \simeq \delta\left(P Q / W^{\mathrm{a}} L\right)_{t},
$$

where $\delta>0$. This specification reflects the logarithmic transformation of (5) and hence is directly comparable to (8) in the first approach.

Needless to say, there are other possible ways to deal with the lack of adequate data in the period before and immediately after the introduction of participation. ${ }^{15}$ For instance, upon rearranging eq. (5) one obtains

$$
\left(W_{\mathrm{t}}-W_{\imath}^{a}\right) L_{\imath} / \pi_{\mathrm{t}}=\gamma+\Delta \gamma D_{\mathrm{t}} .
$$

This expression does not permit a test of the unitary coefficient on $W^{a}$ but it does allow a direct estimation of $\Delta \gamma / \gamma$ upon substitution of $(P Q / \beta)_{t}$ for $\pi_{r}$. This test was performed and the estimates were found to be similar to the second approach estimates which are reported in the next section. Alternatively, one could try to measure $\Delta \gamma$ by comparing $\left(W_{t}-W_{t}^{\mathrm{a}}\right) L_{\mathrm{t}} / \pi_{\mathrm{t}}$ across industries in the period since 1951. The advantage of this approach is that data are available for most of that period and one would not have to resort

\footnotetext{
${ }^{15}$ I am grateful to one of the anonymous referees for bringing these alternative approaches to my attention.
} 
to approximation. However, the direct inter-industry comparison after 1951 is only valid if one is willing to assume that, in the absence of parity participation, labor's bargaining power, $\gamma$, is identical in all the industries. This is very unlikely since there are numerous industry-specific factors such as sex composition, the extent of employment of foreign workers, the industry unemployment rate, and the degree of unionization which are likely to affect the value of $\gamma$. Since an adequate specification of all these factors could not be achieved, the inter-industry comparison was not undertaken.

Embedding eq. (4) into a time series framework raises the question as to whether the dynamic adjustment of the dependent variable is as instantaneous as suggested by eq. (5). In particular, let $\ln W_{1}^{*}$ be the (logarithm of the) long-term equilibrium wage given by (5). Then it is possible that in each period the adjustment toward this equilibrium is only partial and can be characterized by the following process:

$$
\ln W_{t}-\ln W_{t-1}=\kappa\left(\ln W_{t}^{*}-\ln W_{t-1}\right)+\mu_{t}
$$

where $\kappa$ is the partial adjustment coefficient, $0 \leqq \kappa \leqq 1$, and $\mu_{t}$ is an error term with the same properties as $e_{t}$ in (8). Combining (5) and (8) and (9) yields an estimating equation of the form

$$
\ln W_{\mathrm{t}}=\kappa \ln W_{\mathrm{t}}^{\mathrm{a}}+\gamma \kappa\left(\pi / W^{\mathrm{a}} L\right)_{\mathrm{t}}+\Delta \gamma \kappa\left(\pi / W^{\mathrm{a}} L\right)_{\mathrm{t}} D_{\mathrm{t}}+(1-\kappa) \ln W_{\mathrm{t}-1}+\varepsilon_{\mathrm{t}}
$$

where $\varepsilon_{t}=\mu_{t}+\kappa e_{t}$ has the same properties as $\mu_{t}$ and $e_{t}$. In the empirical estimation eq. (10) is approximated using the two approaches outlined earlier.

In order to make eqs. (8) and (10) operational, it is also necessary to specify the best alternative wage, $W^{a}$. Some of my earlier estimates suggest that the 1952 Works constitution Act had no effect on the average hourly wage (earnings) in German manufacturing. Moreover, the overall unemployment rate has been relatively low in Germany and emphasis in the bargaining process tends to be placed on inter-industry rather than international wage differentials. As a result, it is very likely that for an average miner or a steel worker the best alternative wage is either equal or proportional to the manufacturing wage, $W^{m} \cdot{ }^{16}$ Formally, $\left(W_{1}^{a} / W_{t}^{m}\right)=\alpha$ and consequently $\ln W_{1}^{a}=\alpha^{\prime}+\ln W_{t}^{m}$, where $\alpha^{\prime}=\ln \alpha \gtrless 0$ as $\alpha \gtrless 1$. The results reported in the following section reflect this specification, with $\alpha^{\prime}$ and $\kappa \alpha^{\prime}$ being estimated as components of the constant terms in the respective estimating equations. Note that, if $\alpha^{\prime} \neq 0$, it is of course impossible to isolate fully the pure effect of codetermination, $\Delta \gamma / \gamma$, in the first approach.

\footnotetext{
${ }^{16}$ Since my earlier estimates suggest that the 1952 law had no effect on the hourly earnings in German manufacturing, it can be argued that the tests in this paper estimate the effects of the participatory institutions in iron-steel and coal mining as compared to a situation with no participation at all.
} 


\section{Empirical results}

Results in tables 1 and 2 are generated from annual data covering the period 1946-1972. ${ }^{17}$ They are based on the two approaches outlined in the previous section and estimate the effect of the participatory institutions established by the 1951 law in iron-steel and coal mining. The wage data used are average hourly earnings of male workers in the respective industries.

Table 1

Effects of participation on bargaining power and relative wages: Estimates based on the first approach $\left[\left(\pi / W^{a} L\right)_{t} \simeq \text { constant }\right]^{a}{ }^{a}$

\begin{tabular}{ccccccc}
\hline & Const. & $\ln W_{1}^{m}$ & $D_{t}$ & $\ln \hat{W}_{t-1}$ & $R^{2}$ & $\hat{\rho}$ \\
\hline Iron and steel & & & & & & \\
1. & 0.219 & 0.878 & 0.055 & & 0.998 & 0.76 \\
& $(0.050)$ & $(0.035)$ & $(0.025)$ & & & $(0.13)$ \\
2. & 0.211 & 0.823 & 0.053 & 0.060 & 0.998 & 0.67 \\
& $(0.047)$ & $(0.106)$ & $(0.028)$ & $(0.114)$ & $(0.16)$ \\
Coal mining & & & & & & \\
3. & 0.171 & 0.893 & 0.014 & & 0.996 & 0.76 \\
& $(0.076)$ & $(0.050)$ & $(0.036)$ & & & $(0.13)$ \\
4. & 0.437 & 1.270 & -0.034 & -0.539 & 0.998 & 0.74 \\
& $(0.073)$ & $(0.119)$ & $(0.027)$ & $(0.144)$ & & $(0.14)$ \\
\hline
\end{tabular}

a Dependent variable $=\ln W_{1}$; values in parentheses are standard errors; coefficients are estimated under the assumption of first-order autocorrelation in the error terms; $\hat{\rho}$ is the corrected-for first-order autocorrelation coefficient of the residuals; $\ln \hat{W}_{t-1}$ is the predicted value of $\ln W_{1-1}$ estimated by instrumental variables.

Approximating $\left(\pi / W^{\mathrm{a}} L\right)_{t}$ by a constant leads to estimates in table 1 . Partial and a full adjustment scheme results are presented for each industry. In view of the high autocorrelation of the residuals, the equations were estimated by generalized least squares. In the partial adjustment schemes the predicted value of the lagged dependent variable, $\ln \hat{W}_{t-1}$, was estimated by Liviatan's (1963) instrumental variables method. In spite of the admittedly rough approximation inherent in the first approach, $\left(\pi / W^{\mathrm{a}} L\right)_{t}=k$, the results in table 1 provide support for the theoretical model. The constant term, which in this approach equals $\alpha^{\prime}+\gamma k$, is positive and significantly different from zero in all the schemes. The estimated coefficients of $\ln W_{t}^{m}$

\footnotetext{
${ }^{17}$ The participation laws of 1972 and 1976 introduce important modifications of the codetermination system in Germany. In due time it will be of interest to investigate the effects of these laws as well.

EER-B
} 
Table 2

Effects of participation on bargaining power and relative wages: Estimates based on the second approach $\left[\left(\pi / W^{a} L\right)_{t} \simeq \delta\left(P Q / W^{2} L\right)_{t}\right]^{\text {a }}$

\begin{tabular}{|c|c|c|c|c|c|c|c|c|}
\hline & Const. & $\ln W_{1}^{m}$ & $\left(P Q / W^{\prime} L\right)$ & $\left(P Q / W^{a} L\right), D_{t}$ & $\ln W_{t-1}$ & $R^{2}$ & $h$ & $\hat{\rho}$ \\
\hline Iron and steel & & & & & . & & & \\
\hline 1. & $\begin{array}{c}-0.016 \\
(0.054)\end{array}$ & $\begin{array}{c}0.969 \\
(0.020)\end{array}$ & $\begin{array}{c}82.634 \\
(29.256)\end{array}$ & $\begin{array}{c}7.308 \\
(14.349)\end{array}$ & & 0.999 & & $\begin{array}{c}0.31 \\
(0.19)\end{array}$ \\
\hline 2. & $\begin{array}{c}0.040 \\
(0.024)\end{array}$ & $\begin{array}{c}0.778 \\
(0.141)\end{array}$ & $\begin{array}{c}53.985 \\
(16.900)\end{array}$ & $\begin{array}{c}7.268 \\
(14.107)\end{array}$ & $\begin{array}{c}0.184 \\
(0.149)\end{array}$ & 0.999 & 1.65 & \\
\hline \multicolumn{9}{|l|}{ Coal mining } \\
\hline 3. & $\begin{array}{c}0.223 \\
(0.161)\end{array}$ & $\begin{array}{c}0.874 \\
(0.054)\end{array}$ & $\begin{array}{c}-3.400 \\
(18.527)\end{array}$ & $\begin{array}{c}2.247 \\
(5.310)\end{array}$ & & 0.996 & & $\begin{array}{c}0.73 \\
(0.14)\end{array}$ \\
\hline 4. & $\begin{array}{c}0.295 \\
(0.131)\end{array}$ & $\begin{array}{c}1.317 \\
(0.135)\end{array}$ & $\begin{array}{c}24.057 \\
(15.072)\end{array}$ & $\begin{array}{c}-8.636 \\
(4.926)\end{array}$ & $\begin{array}{c}-0.583 \\
(0.171)\end{array}$ & 0.998 & & $\begin{array}{c}0.70 \\
(0.16)\end{array}$ \\
\hline
\end{tabular}

Dependent variable $=\ln W_{t}$; values in parentheses are standard errors; $h$ is the Durbin (1970) test statistic for autocorrelation when a lagged dependent variable is present; schemes 1 , 3 and 4 are estimated under the assumption of first-order autocorrelation in the error terms; $\hat{\rho}$ is the corrected-for first-order autocorrelation coefficient of the residuals; in scheme $4 \ln W_{t-1}$ is the predicted value, $\ln \hat{W}_{t-1}$, estimated by instrumental variables.

are fairly close to the theoretically predicted value of $1.0,{ }^{18}$ and have very low standard errors - a result which suggests that $W_{l}^{\mathrm{m}}$ is indeed a good candidate for $W_{r}^{a}$. The full adjustment model generates a positive $5.5 \%$ estimate of the wage effect of participation in iron and steel. The corresponding partial adjustment model produces a $5.3 \%$ estimate of this effect. In contrast, the estimated wage effect in coal mining is not significantly different from zero in either scheme. Hence, the results in table 1 suggest that with the introduction of participation wages increased by about $5.3 \%$ to $5.5 \%$ in iron and steel but that they remained unchanged in coal mining.

Assuming that the manufacturing wage is indeed the best alternative wage, $\alpha^{\prime}=0$, it is possible to obtain estimates of $\Delta \gamma / \gamma$ by dividing in each equation the estimated coefficient on $D_{t}$ by the estimated constant term. Both the full and partial adjustment schemes suggest that as a result of the 1951 Codetermination Law labor's bargaining power increased by $25 \%$ in iron-steel but remained unchanged in coal mining.

Since the estimated coefficients on $\ln W_{t}^{m}$ are close to the theoretically predicted value of 1.0 , the tests were also replicated with the restriction

\footnotetext{
${ }^{18}$ In the partial adjustment schemes the coefficient of $\ln W_{i}^{m}$ should be equal to $k$. When this coefficient is divided by $\kappa$ obtained from the coefficient of $\ln W_{1-1}$, the resulting value is again very close to 1.0 .
} 
imposed on the data. The resulting estimated effects were virtually identical to the unrestricted estimates.

The results in table 2 reflect the assumption that net profit, $\pi_{t}$, varies proportionally to gross revenue, $(P Q)_{r}$. The estimate of labor's preparticipation bargaining power is given by the coefficient of $\left(P Q / W^{a} L\right)_{r}$. This coefficient is positive and significant in iron and steel, thus suggesting the labor's pre-participation bargaining power had been positive in this industry. In contrast, the estimate labor's pre-participation power is not found to be significantly different from zero in coal mining. The coefficients of $\ln W_{1}^{m}$ are again close to their theoretically predicted value of 1.0 . If $W_{t}^{m}$ in fact constitutes the best alternative wage, $W_{t}^{\mathrm{a}}$, then the value of the constant term, which in this second approach represents only the deviation of $W_{t}^{m}$ from $W_{t}^{\mathrm{a}}\left(\ln \alpha=\alpha^{\prime}\right)$, ought to be close to zero. As the results in table 2 indicate, with the exception of scheme 4 , it is impossible to reject this hypothesis at conventional significance test levels. The estimated effect of participation on labor's bargaining power and wages is positive but statistically insignificant in both iron and steel schemes and in the full adjustment scheme in coal mining. The partial adjustment model in coal mining generates a negative effect which, however, is also not statistically significant from zero.

Since the estimates of the first three schemes in table 2 suggests that (a) the coefficient on $\ln W_{t}^{m}$ is not significantly different from its theoretically predicted value of 1.0 , and (b) the constant term, $\alpha^{\prime}$, is not significantly different from zero, the test of the full adjustment scheme was also performed with these constraints imposed on the model. This specification yields virtually identical coefficient estimates of $\gamma$ and $\Delta \gamma$ as the corresponding scheme in table 2 and reduces substantially the estimated standard errors. While this reduction clearly sharpens our ability to test the hypothesis about the bargaining power and wage effects of participation, the estimated ratio of $\Delta \gamma$ to its standard error is still too low to permit the conclusion that $\Delta \gamma>0$ in iron and steel at conventional significance test levels.

\section{Conclusions}

In view of the fact that the results in tables 1 and 2 are based on approximations, conclusions should be drawn with caution. The estimates in table 1 indicate that the establishment of codetermination was accompanied by a wage increase in iron and steel industry but not in coal mining. These estimates support my (1981) findings, which were obtained within an alternative empirical framework. Both studies suggest that the differences between the codetermination system established in iron-steel and in coal 
mining may be significant enough to have varying effects on labor's bargaining power in the two industries. However, the results in table 2 indicate that the iron and steel wage effect could possibly be due to an increase in the subject of bargaining, $\pi / W^{a} L$, rather than to a shift in labor's bargaining power, $\Delta \gamma$. The results in table 2 also support the earlier finding in table 1 that $\Delta \gamma=0$ in coal mining.

If one proceeds with the idea that the shift in the iron and steel wage is due to an increase in the subject of bargaining rather than in labor's bargaining power, then the question naturally arises as to whether the increase in $\pi / W^{a} L=\delta\left(P Q / W^{a} L\right)$ is due to a codetermination-engendered rise in productivity or to an increase in the product price which may or may not be related to codetermination. Blumenthal's (1956) study of the West German iron and steel industry supports the latter interpretation. Using industry-level data I have recently (1982a) tested the effect of codetermination on productivity within a production function framework and could not detect any significant effect. Hence if one interprets the findings in the present paper as suggesting that the introduction of codetermination had no significant effect on labor's bargaining power, related findings seem to indicate that the productivity impact of codetermination was insignificant as well.

While these results are interesting, more empirical research in this area is clearly needed. The phenomenon of worker representation on the boards as well as of other forms of participation are spreading in most developed countries, including the United States and Great Britain. At the same time, the theoretical literature on the subject is very limited and empirical evidence is virtually non-existent.

\section{References}

Ashenfelter, O. and G. Johnson, 1969, Bargaining theory, trade unions and industrial strike activity, American Economic Review 59, no. 1, March.

Blumenthal, W.M., 1956, Codetermination in the German steel industry (Industrial Relations Section, Princeton University, Princeton, NY).

Commons, J.R., 1934, Institutional economics: Its place in political economy (Macmillan, New York).

Durbin, T., 1970, Testing for serial correlation in least-squares regression when some of the regressors are lagged dependent variables, Econometrica 38, May.

European Economic Community, 1970, Proposal for a council regulation embodying a statute for a European company, Bulletin of the E.E.C., Suppl. 8.

European Economic Community, 1975, Statute for European companies: Amended proposal for a regulation, Bulletin of the E.E.C., Suppl. 4.

Farber, H., 1978, Bargaining theory, wage outcomes, and the occurrence of strikes: An econometric analysis, American Economic Review 68, No. 3, June.

Fürstenberg, F., 1969, Workers' participation in management in the Federal Republic of Germany, International Institute for Labour Studies Bulletin, No. 6, June.

Fürstenberg, F., 1977, West German experience with industrial democracy, Annals of the American Academy of Political and Social Science, May. 
Kochan, T.A., 1980, Collective bargaining and industrial relations: From theory to policy and practice (Irwin, Homewood, IL).

Livitian, N., 1963, Consistent estimation of distributed lags, International Economic Review 4.

Pigou, A.C., 1938, Economics of welfare, 4th ed. (Macmillan, London).

Schregle, J., 1976, Workers' participation in decisions within undertaking, International Labour Review 113, no. 1, Jan./Feb.

Steinherr, A., 1977, On the efficiency of profit sharing and labor participation in management, The Bell Journal of Economics 8, no. 2, Autumn.

Sturmthal, A.F., 1964, Workers councils (Harvard University Press, Cambridge, MA).

Svejnar, J., 1981, Relative wage effects of unions, dictatorship and codetermination: Econometric evidence from Germany, The Review of Economics and Statistics 63, no. 2, May.

Svejnar, J., 1982a, Codetermination and productivity: Empirical evidence from the Federal Republic of Germany, in: D. Jones and J. Svejnar, eds., Participatory and selfmanaged firms: Evaluating of economic performance (Lexington Books, Lexington, MA)

Svejnar, J., 1982b, On the theory of a participatory firm, Journal of Economic Theory, Forthcoming.

Vanek, J., 1970, The general theory of labor-managed market economies (Cornell University Press, Ithaca, NY).

Vollmer, R.J., 1976, Industrial democracy in Germany, Mimeo., June (Embassy of the Federal Republic of Germany, London).

Windmuller, J.P., 1977, Industrial democracy and industrial relations, The Annals of the American Academy of Political and Social Science 431, May. 